OPEN ACCESS

Edited by:

Firas H. Kobeissy,

University of Florida, United States

Reviewed by:

Pushpa Sharma,

Uniformed Services University of the

Health Sciences, United States

Riyad El-Khoury,

American University of

Beirut, Lebanon

*Correspondence:

Jignesh D. Pandya

jignesh.d.pandya.civ@mail.mil

Specialty section:

This article was submitted to

Neurotrauma,

a section of the journal

Frontiers in Neurology

Received: 26 July 2018

Accepted: 22 May 2019

Published: 11 June 2019

Citation:

Pandya JD, Leung $L Y$, Yang $X$

Flerlage WJ, Gilsdorf JS,

Deng-Bryant Y and Shear DA (2019)

Comprehensive Profile of Acute

Mitochondrial Dysfunction in a

Preclinical Model of Severe

Penetrating TBI.

Front. Neurol. 10:605

doi: 10.3389/fneur.2019.00605

\section{Comprehensive Profile of Acute Mitochondrial Dysfunction in a Preclinical Model of Severe Penetrating TBI}

\author{
Jignesh D. Pandya ${ }^{1 *}$, Lai Yee Leung 1,2, Xiaofang Yang ${ }^{1}$, William J. Flerlage ${ }^{1}$, \\ Janice S. Gilsdorf ${ }^{1}$, Ying Deng-Bryant ${ }^{1}$ and Deborah A. Shear ${ }^{1}$
}

${ }^{1}$ Brain Trauma Neuroprotection Branch, Center for Military Psychiatry and Neuroscience, Walter Reed Army Institute of Research, Silver Spring, MD, United States, ${ }^{2}$ Department of Surgery, Uniformed Services University of the Health Sciences, Bethesda, MD, United States

Mitochondria constitute a central role in brain energy metabolism, and play a pivotal role in the development of secondary pathophysiology and subsequent neuronal cell death following traumatic brain injury (TBI). Under normal circumstances, the brain consumes glucose as the preferred energy source for adenosine triphosphate (ATP) production over ketones. To understand the comprehensive picture of substrate-specific mitochondrial bioenergetics responses following TBI, adult male rats were subjected to either 10\% unilateral penetrating ballistic-like brain injury (PBBI) or sham craniectomy ( $n=5$ animals per group). At $24 \mathrm{~h}$ post-injury, mitochondria were isolated from pooled brain regions (frontal cortex and striatum) of the ipsilateral hemisphere. Mitochondrial bioenergetics parameters were measured ex vivo in the presence of four sets of metabolic substrates: pyruvate+malate (PM), glutamate+malate (GM), succinate (Succ), and $\beta$-hydroxybutyrate+malate (BHBM). Additionally, mitochondrial matrix dehydrogenase activities [i.e., pyruvate dehydrogenase complex (PDHC), alpha-ketoglutarate dehydrogenase complex $(\alpha-\mathrm{KGDHC})$, and glutamate dehydrogenase $(\mathrm{GDH})]$ and mitochondrial membrane-bound dehydrogenase activities [i.e., electron transport chain (ETC) Complex I, II, and IV] were compared between $\mathrm{PBBl}$ and sham groups. Furthermore, mitochondrial coenzyme contents, including $\mathrm{NAD}_{(\mathrm{t})}$ and $\mathrm{FAD}_{(\mathrm{t})}$, were quantitatively measured in both groups. Collectively, PBBI led to an overall significant decline in the ATP synthesis rates (43-50\%; ${ }^{*} p<0.05$ vs. sham) when measured using each of the four sets of substrates. The PDHC and $\mathrm{GDH}$ activities were significantly reduced in the $\mathrm{PBBI}$ group (42-53\%; * $p<0.05$ vs. sham), whereas no significant differences were noted in $\alpha-K G D H C$ activity between groups. Both Complex I and Complex IV activities were significantly reduced following PBBI (47-81\%; * $p<0.05$ vs. sham), whereas, Complex II activity was comparable between groups. The $N A D_{(t)}$ and $F A D_{(t)}$ contents were significantly decreased in the $\mathrm{PBBI}$ group $\left(27-35 \% ;{ }^{*} p<0.05\right.$ vs. sham). 
The decreased ATP synthesis rates may be due to the significant reductions in brain mitochondrial dehydrogenase activities and coenzyme contents observed acutely following PBBI. These results provide a basis for the use of "alternative biofuels" for achieving higher ATP production following severe penetrating brain trauma.

Keywords: traumatic brain injury (TBI), penetrating ballistic-like brain injury (PBBI), alternative biofuels, brain energy metabolism, energy crisis, mitochondria preferred substrates, dehydrogenase activities, therapeutics

\section{HIGHLIGHTS}

- Metabolic substrates mediated decline in ATP synthesis following TBI.

- Decreased brain mitochondrial dehydrogenase activities following TBI.

- Decreased brain mitochondrial $\mathrm{NAD}_{(\mathrm{t})}$ and $\mathrm{FAD}_{(\mathrm{t})}$ contents following TBI.

- Alternative biofuels are recommended to overcome energy crisis after TBI.

\section{INTRODUCTION}

There is a growing interest in further understanding of the brain metabolic responses following traumatic brain injury (TBI) to facilitate acute critical care management of TBI patients; and develop novel targeted therapeutic interventions for TBI. TBI produces immediate hypo- or hyper-metabolic responses, which are indicated by the changes in the cerebral metabolic rate of glucose (CMRglc), blood flow and oxygenation. Although the magnitude and duration of CMRglc metabolic pattern varies with the injury severity, species, and the type of brain injury models, all studies consistently showed transient hyper-function followed by prolonged depression during acute to sub-acute phase of secondary injury in both pre-clinical injury models and in TBI patients (1-4) This metabolic shift has been observed in different experimental injury models and clinically over the acute and sub-acute phases following TBI (5-8). During this period, concomitant increases in anaerobic lactate accumulation due to glycolysis was evident in both tissue and extracellular space (3, 5, 9-12). Therefore, a decline in brain energy resulting from TBI is a significant issue that remains to be addressed in the management of TBI (13). In fact, several clinical reviews have recommended early intervention of supplying energy intermediate substrates for improvements in mortality and neurological outcomes following TBI (13-15).

Mitochondria play a pivotal role in maintaining cellular energy homeostasis critical to neuronal cell survival. Previous studies have implicated mitochondrial dysfunction as a

Abbreviations: ATP, Adenosine $5^{\prime}$-Triphosphate; $\alpha$-KGDHC, alpha-Ketoglutarate Dehydrogenase Complex; ETC, Electron Transport Chain; FAD, Flavin Adenine Dinucleotide (oxidized); $\mathrm{FADH}_{2}$, Flavin Adenine Dinucleotide (reduced); $\mathrm{FAD}_{(\mathrm{t})}$, Flavin Adenine Dinucleotide (total content); GDH, Glutamate Dehydrogenase; NAD, Nicotinamide Adenine Dinucleotide (oxidized); NADH, Nicotinamide Adenine Dinucleotide (reduced); $\mathrm{NAD}_{(\mathrm{t})}$, Nicotinamide Adenine Dinucleotide (total content); OXPHOS, Oxidative Phosphorylation; PBBI, Penetrating BallisticLike Brain Injury; PDHC, Pyruvate Dehydrogenase Complex; TBI, Traumatic Brain Injury; TCA, Tricarboxylic Acid Cycle. prominent feature of TBI. Abnormal mitochondrial functions include reduced respiratory rates, depleted energy stores (i.e., adenosine triphosphate, ATP), increased free radical production, mitochondrial calcium overload, and early opening of mitochondrial permeability transition pore (mPTP) (16-18). The increased production of free radicals (i.e., reactive oxygen and nitrogen species, ROS/RNS) overwhelms endogenous antioxidants resulting in oxidative stress $(19,20)$. Additionally, mitochondria release many pro-inflammatory, apoptotic and necrotic signaling factors contributing to cell death overtime (17, 21-23).

In the current study, we hypothesized that TBI leads to altered utilization of glucose and ketone intermediates for brain energy production. We compared mitochondrial ATP synthesis rates for glucose and ketone intermediate substrates (i.e., pyruvate, glutamate, succinate, and $\beta$-hydroxybutyrate), each using an identical ex vivo condition. Additionally, mitochondrial dehydrogenase activities, and coenzyme contents were quantified following PBBI vs. sham. Collectively, our results provide a basis for the use of therapeutic drugs and nutraceuticals as "alternative biofuels" for the management of energy crisis following brain trauma.

\section{MATERIALS AND METHODS}

\section{Materials}

Mannitol, sucrose, bovine serum albumin (BSA), N2-hydroxyethylpiperazine- $\mathrm{N}^{\prime}$-2-ethanesulfonic acid (HEPES) potassium salt, potassium phosphate monobasic anhydrous $\left(\mathrm{KH}_{2} \mathrm{PO}_{4}\right)$, magnesium chloride $\left(\mathrm{MgCl}_{2}\right)$, ethylene-diamine-tetra-acetic acid (EDTA), ethylene-glycoltetra-acetic acid (EGTA), pyruvate, malate, glutamate, succinate, $\beta$-hydroxybutyrate, $\alpha$-ketoglutarate, adenosine$5^{\prime}$-diphosphate (ADP), oligomycin A, carbonyl cyanide 4-(trifluoromethoxy)phenylhydrazone (FCCP), rotenone, succinate, dimethyl sulfoxide (DMSO) were purchased from Sigma-Aldrich (St. Louis, MO, USA). BCA protein assay kit was purchased from Pierce (Rockford, IL). Both $\mathrm{NAD}_{(\mathrm{t})}$ and $\mathrm{FAD}_{(\mathrm{t})}$ content assessments kits were purchased from Sigma-Aldrich (St. Louis, MO, USA). Mitochondrial substrates and inhibitors stock solutions were prepared and aliquots stored at $-80^{\circ} \mathrm{C}$.

\section{Animals}

Adult male Sprague-Dawley rats (280-350g, Charles River Laboratories, Raleigh, VA) were used for this study. Animals were housed individually under a normal $12 \mathrm{~h}$ light/dark cycle (lights on at 0600 EST) in a well-ventilated facility accredited by the Association for Assessment and Accreditation of Laboratory 
Animal Care (AAALAC), and allowed $7 \mathrm{~d}$ for acclimation to the housing facility before any procedures were performed. All experimental procedures were approved by the Institutional Animal Care and Use Committee (IACUC) at Walter Reed Army Institute of Research (WRAIR). Animal studies were conducted in compliance with the Animal Welfare Act, the Guide for the Care and Use of Laboratory Animals (National Research Council), and other federal statutes and regulations relating to animals and experiments involving animals.

\section{Penetrating Ballistic-Like Brain Injury (PBBI) Model}

All surgical procedures were performed under isoflurane anesthesia (3-5\% for induction and $2 \%$ for maintenance) and aseptic conditions with careful monitoring of physiological vital signs. The PBBI surgery was performed as described previously (24-26). The PBBI apparatus consists of a specifically designed probe (Kadence Science, Lake Success, NY), a stereotaxic frame (Kopf, Tujunga, CA) and a hydraulic pressure-pulse generator (4B080; MITRE, MA). The probe was made of a 20G stainless steel tube with fixed perforations along one end which was sealed by a piece of airtight elastic tubing. The probe was secured on the probe holder with the un-perforated end attached to the pulse generator, angled at $50^{\circ}$ from the vertical axis and $25^{\circ}$ counter clockwise from the midline. Core body temperature was maintained normothermic $\left(\sim 37^{\circ} \mathrm{C}\right)$ using a heating blanket (Harvard Apparatus, South Natick, MA). Under isoflurane anesthesia (2\%; in air/oxygen mixture), rat head was secured in the stereotaxic device for insertion of the PBBI probe. After a midline scalp incision, a right frontal cranial window (diameter $=4 \mathrm{~mm}$ ) was created using a dental drill to expose the right frontal pole $(+4.5 \mathrm{~mm} \mathrm{AP},+2 \mathrm{~mm} \mathrm{ML}$ to bregma). The PBBI probe was then advanced through the cranial window into the right hemisphere to a depth of $1.2 \mathrm{~cm}$ from the surface of the brain. Once the probe was in place, the pulse generator was activated by a computer to release a pressure pulse calibrated to produce a rapid expansion of the water-filled elastic tubing to create an elliptical shaped balloon (diameter $=0.633 \mathrm{~mm}$ ) to a volume equal to $10 \%$ of the total brain volume. This rapid inflation/deflation (duration $=40 \mathrm{~ms}$ ) produced a temporary cavity in the brain. After deflation, the probe was immediately retracted from the brain and the cranial opening was sealed with sterile bone wax, and the skin incision was closed with wound clips. All sham animals underwent craniectomy only with no insertion of the PBBI probe.

\section{Mitochondrial Isolation}

At $24 \mathrm{~h}$ post-PBBI, animals were asphyxiated with $\mathrm{CO}_{2}$, rapidly decapitated, and the brains were removed and placed in mitochondrial isolation buffer at $4^{\circ} \mathrm{C}$. From ipsilateral hemisphere of PBBI and sham injured brains, the frontal cortex and striatum regions were isolated and pooled together for mitochondrial isolation. The pooled regions represent the injury core and perilesional area of the injury, where extensive cell death may occur due to the initial mechanical force (primary injury) and excitotoxicity (secondary injury). Mitochondria were isolated under identical experimental conditions using an established Ficoll-based mitochondrial ultra-purification procedure (27-29). All isolation steps were performed at $4^{\circ} \mathrm{C}$ using mitochondrial isolation buffer (MIB) composed of $215 \mathrm{mM}$ Mannitol, $75 \mathrm{mM}$ Sucrose, 0.1\% BSA, $1 \mathrm{mM}$ EGTA, and $20 \mathrm{mM}$ HEPES at $\mathrm{pH}$ 7.2. Tissue homogenates were centrifuged at $1,300 \times \mathrm{g}$ for $3 \mathrm{~min}$ to remove cell debris and nuclei, and collected supernatants were then centrifuged at $13,000 \times \mathrm{g}$ for $10 \mathrm{~min}$ to pellet crude mitochondria. The resultant crude mitochondrial samples were re-suspended in $500 \mu \mathrm{l}$ of MIB and kept in a nitrogen cell decompression bomb (model 4,639, Parr Instrument Co., Moline, IL, USA) at 1,200 psi for $10 \mathrm{~min}$ at $4^{\circ} \mathrm{C}$ to release mitochondria from synaptosomes. The mitochondrial samples were then placed on top of a discontinuous Ficoll gradient (layered $2 \mathrm{ml}$ of $7.5 \%$ Ficoll solution on top of $2 \mathrm{ml}$ of $10 \%$ Ficoll solution) and centrifuged at $100,000 \times \mathrm{g}$ for $30 \mathrm{~min}$ at $4^{\circ} \mathrm{C}$ using a Beckman ultracentrifuge with SW55Ti rotor (Beckman Coulter, IN, USA). Ultrapure mitochondrial pellets formed at the bottom were carefully collected, avoiding contamination from ruptured synaptic plasma membranes isolated at the interface. These pure mitochondrial pellets were resuspended in $2 \mathrm{ml} \mathrm{MIB}{ }^{-}$(without $1 \mathrm{mM}$ EGTA buffer) and centrifuged at $10,000 \times \mathrm{g}$ for $10 \mathrm{~min}$. The washed mitochondrial pellets were finally re-suspended in $\mathrm{MIB}^{-}$to achieve desirable mitochondrial protein concentration $(\sim 10$ $\mathrm{mg} / \mathrm{ml}$ ) for mitochondrial function assessments. Mitochondrial protein concentration was determined using the BCA protein assay kit measuring absorbance at $562 \mathrm{~nm}$ with BioTek Synergy HT plate reader (Winooski, VT, USA). Following the completion of mitochondrial isolation, mitochondrial respiration was measured within $\sim 3 \mathrm{~h}$ post-isolation; whereas remaining samples were stored at $-80^{\circ} \mathrm{C}$ for dehydrogenase activities and coenzyme content assessments.

\section{Mitochondrial Respiration}

The real-time mitochondrial respiration was assessed by the Clark-type oxygen electrode in a continuously stirred, sealed chamber thermostatically maintained at $37^{\circ} \mathrm{C}$ (Oxytherm System, Hansatech Instruments Ltd.,), as described previously $(16,27,29)$. Approximately $50 \mu \mathrm{g}$ of mitochondrial protein was added into the chamber containing $250 \mu \mathrm{l}$ of $\mathrm{KCl}-$ based respiration buffer $(125 \mathrm{mM} \mathrm{KCl}, 2 \mathrm{mM} \mathrm{MgCl}, 2.5 \mathrm{mM}$ $\mathrm{KH}_{2} \mathrm{PO}_{4}, 0.1 \%$ BSA, $20 \mathrm{mM}$ HEPES, pH 7.2). After $1 \mathrm{~min}$ equilibration, the State II respiration was initiated by the addition of either one of the four separate sets of metabolic substrates [e.g., pyruvate+malate (PM), glutamate+malate (GM), succinate (Succ), or $\beta$-hydroxybutyrate+malate (BHBM)] in the respiration chamber. The State III respiration rate was measured subsequently after addition of two boluses of $150 \mu \mathrm{M}$ ADP followed by State IV respiration rates that were measured by the addition of $1 \mu \mathrm{M}$ oligomycin. The mitochondrial uncoupler FCCP $(1 \mu \mathrm{M})$ was added at last to measure uncoupling respiration rates (State $\mathrm{V}$ ) in the chamber. For each mitochondrial sample, all four substrates driven mitochondrial respiration were individually performed; and their respiration rates (i.e., from State II to State V) were recorded to calculate oxygen consumption rates (nmols $\mathrm{O}_{2}$ consumed/mg protein). 


\section{Mitochondrial Dehydrogenase Activity Assessments}

All remaining $-80^{\circ} \mathrm{C}$ stored mitochondrial samples were freezethawed and sonicated together three times before measuring enzyme activities at $37^{\circ} \mathrm{C}$. Mitochondrial matrix dehydrogenase activities [i.e., pyruvate dehydrogenase complex (PDHC), alpha-ketoglutarate dehydrogenase complex ( $\alpha$-KGDHC), and glutamate dehydrogenase (GDH)] and membrane-bound dehydrogenase activities (i.e., electron transport chain (ETC) Complex I, II, and IV) were performed by either absorbance or florescence based assays using an automated 96-well microplate reader (BioTek Instruments, INC, Winooski, VT, USA) as described below (27, 30-34).

\section{Pyruvate Dehydrogenase Complex (PDHC) Enzyme Activity}

The mitochondrial gate keeper enzyme PDHC catalyzes the oxidative decarboxylation of pyruvate to acetyl-CoA and thereby links the glycolysis pathway to TCA cycle. It provides intermediate acetyl-CoA substrates to TCA cycle for energy metabolism. The first subunit of the PDHC i.e., pyruvate dehydrogenase $(\mathrm{PDH})$ enzyme activity was measured using previously described methods with slight modification. The assay was performed using a substrates, inhibitor and cofactor mixtures in a buffer containing $50 \mathrm{mM} \mathrm{KCl,} 10 \mathrm{mM}$ HEPES $\mathrm{pH} 7.4,0.3 \mathrm{mM}$ thiamine pyrophosphate (TPP), $10 \mu \mathrm{M} \mathrm{CaCl}_{2}$, $0.2 \mathrm{mM} \mathrm{MgCl}_{2}, 5 \mathrm{mM}$ pyruvate, $1 \mu \mathrm{M}$ rotenone, and $0.2 \mathrm{mM}$ NAD. Ficoll-purified mitochondrial protein (8 $\mu \mathrm{g} /$ well) was assayed in triplicate for each sample. The enzyme reaction was started by the addition of $0.14 \mathrm{mM}$ coenzyme A. The fluorescence based enzyme activity assay was performed (Ex $\lambda 340 \mathrm{~nm}$, Em $\lambda 460 \mathrm{~nm}$ ), and increment of NADH fluorescence was measured per minute interval. The PDHC activity was calculated and expressed as \% change in PBBI vs. sham.

\section{Glutamate Dehydrogenase (GDH) Enzyme Activity}

The mitochondrial enzyme GDH catalyzes the reversible oxidative deamination of glutamate to $\alpha$-ketoglutarate and serves as a key link between anabolic and catabolic pathways. The GDH enzyme activity (10 $\mu \mathrm{g} /$ well) assay was determined (i.e., absorbance $450 \mathrm{~nm}$ ) by a coupled enzyme colorimetric assay (100 $\mu \mathrm{l}$ assay volume) in which glutamate was consumed by $\mathrm{GDH}$ generating $\mathrm{NADH}$, which in turn reacts with a probe proportional to the GDH activity present. One unit of GDH is the amount of enzyme that generates 1 mmols of $\mathrm{NADH}$ per minute at $\mathrm{pH} 7.6$ at $37^{\circ} \mathrm{C}$. The $\mathrm{GDH}$ assay was performed using commercially available assay kit (Sigma-Aldrich, USA) and the data was expressed as \% change in PBBI vs. sham.

\section{$\alpha$-Ketoglutarate Dehydrogenase Complex $(\alpha-$ KGDHC) Enzyme Activity}

The first subunit form of the mitochondrial enzyme $\alpha$-KGDHC, 2-oxoglutarate dehydrogenase complex catalyzes the conversion of 2-oxoglutarate to succinyl-CoA and $\mathrm{CO}_{2}$ in the TCA cycle. The first subunit of the $\alpha$-KGDHC i.e., $\alpha$-ketoglutarate dehydrogenase ( $\alpha-\mathrm{KGDH})$ activity (10 $\mu \mathrm{g} /$ well) assay was determined (i.e., absorbance $450 \mathrm{~nm}$ ) by a coupled enzyme colorimetric assay (100 $\mu$ l assay volume) in which 2-oxoglutarate was consumed by $\alpha-\mathrm{KGDH}$ generating $\mathrm{NADH}$, which in turn reacts with a probe proportional to the $\alpha-\mathrm{KGDH}$ activity present. One unit of $\alpha$-ketoglutarate dehydrogenase activity is the amount of enzyme that generates $1 \mathrm{mmols}$ of $\mathrm{NADH}$ per minute at $\mathrm{pH}$ 7.5 at $37^{\circ} \mathrm{C}$. The $\alpha-\mathrm{KGDH}$ assay was performed by commercially available assay kit (Sigma-Aldrich, USA) and the data was expressed as \% change in PBBI vs. sham.

\section{Complex I (NADH Dehydrogenase) Enzyme Activity}

Complex I, or NADH dehydrogenase, is the first enzyme of the mitochondrial ETC. It catalyzes the transfer of electrons from NADH to coenzyme Q. The Complex I activity assay was performed in $25 \mathrm{mM} \mathrm{KH}_{2} \mathrm{PO}_{4}$ buffer ( $\mathrm{pH}$ 7.2) containing $5 \mathrm{mM} \mathrm{MgCl}_{2}, 1 \mathrm{mM} \mathrm{KCN}, 1 \mathrm{mg} / \mathrm{ml}$ BSA and $150 \mu \mathrm{M} \mathrm{NADH}$. Mitochondrial protein $(6 \mu \mathrm{g} /$ well $)$ was added to the reaction buffer, and the assay was performed in the absence or presence of rotenone $(10 \mu \mathrm{M})$ to determine rotenone-insensitive and rotenone-sensitive enzyme activities. The reaction was started by the addition $50 \mu \mathrm{M}$ of coenzyme $\mathrm{Q}_{1}$. The fluorescence based enzyme activity assay was performed (Ex $\lambda 340 \mathrm{~nm}$, Em $\lambda$ $460 \mathrm{~nm}$ ), and decrease in fluorescence of NADH was measured per 1 min intervals. The Complex I activity was calculated and expressed as \% change in PBBI vs. sham.

\section{Complex II (Succinate Dehydrogenase) Enzyme Activity}

Complex II, or succinate dehydrogenase, is the only membranebound enzyme of the TCA cycle that participates additionally in the ETC activities. The FAD containing enzyme catalyzes the oxidation of succinate to fumarate with the reduction of ubiquinone to ubiquinol. The enzyme activity was determined by coupled reactions measuring the change in absorbance of a dye, 2,6-Dichlorophenolindophenol (DCIP), at $600 \mathrm{~nm}$ using a BioTek Synergy HT plate reader (BioTek, Winooski, VT, USA). Briefly, the mitochondrial protein $(8 \mu \mathrm{g} /$ well $)$ was added to $200 \mathrm{mM} \mathrm{KH} \mathrm{PO}_{4}$ (pH 7.0) assay buffer containing $20 \mathrm{mM} \mathrm{K}$ succinate as substrate for Complex II, $10 \mu \mathrm{M}$ EDTA, $0.01 \%$ Triton $\mathrm{X}-100,1 \mu \mathrm{g}$ coenzyme $\mathrm{Q}_{10}$ in a total assay volume of $100 \mu \mathrm{l} /$ well. The Complex I inhibitor rotenone was not included in the assay system. The $30 \mu \mathrm{l}$ of concentrated DCIP dye (20 $\mathrm{mg} \%$ ) was added to each well, giving initial absorbance readings near $0.9-1.0$. In the reaction, succinate is oxidized to fumarate and reduces DCIP dye (blue color) into $\mathrm{DCIPH}_{2}$ (colorless) compound. During this succinate-DCIP oxidation-reduction, coenzyme $\mathrm{Q}_{10}$ acts as an intermediate compound that transiently accepts electrons and further donates to DCIP. The decrease in DCIP absorbance was measured per minute based on nmols of succinate oxidized; and expressed as \% change in PBBI vs. sham.

\section{Complex IV (Cytochrome C Oxidase) Enzyme Activity}

Complex IV is the terminal electron acceptor enzyme in the mitochondrial ETC complexes. It receives an electron 
from four cytochrome $\mathrm{c}$ molecules and transfers them to one oxygen molecule to convert molecular oxygen; together with translocating four protons into intermembrane space from mitochondrial matrix to establish a transmembrane electrochemical potential $(\Delta \Psi \mathrm{m})$. The cytochrome c oxidase activity was measured in $10 \mathrm{mM} \mathrm{KH}_{2} \mathrm{PO}_{4}$ buffer by co-incubating mitochondrial protein $(6 \mu \mathrm{g} /$ well). The reaction was initiated by adding $50 \mu \mathrm{M}$ reduced cytochrome c. The rate of oxidation of cytochrome $\mathrm{c}$ was measured by detecting decrease in absorbance of reduced cytochrome $c$ at $550 \mathrm{~nm}$ per $1 \mathrm{~min}$ intervals. The Complex IV activity was calculated and expressed as \% change in PBBI vs. sham.

\section{Mitochondrial Coenzyme Contents $N A D_{(t)}$ Quantification}

Nicotinamide adenine dinucleotide (NAD) is an enzymatic cofactor involved in many redox reactions. NAD functions as an electron carrier, cycling between the oxidized (NAD) and reduced $(\mathrm{NADH})$ forms. In addition to its role in redox reactions, NAD plays critical roles in several cellular metabolic reactions. In a colorimetric assay (i.e., absorbance $450 \mathrm{~nm}$ ), the total form of NAD or $\mathrm{NAD}_{(\mathrm{t})}$ (i.e., the combined form of both NAD and $\mathrm{NADH}$ ) was quantified using commercially available NAD quantification kit (Sigma-Aldrich, USA). This assay is specific for $\mathrm{NAD}_{(\mathrm{t})}$ and does not detect NADP nor NADPH. Briefly, mitochondrial proteins $(100 \mu \mathrm{g})$ were re-suspended in $100 \mu \mathrm{l}$ of NAD extraction buffer. Samples were vortexed and freezethawed three times, and any remaining insoluble debris was finally pelleted at $13,000 \times \mathrm{g}$ for $10 \mathrm{~min}$ and discarded. The extracted supernatant was transferred into a new tube and stored for measurement $\left(50 \mu \mathrm{g} /\right.$ well). The $\mathrm{NAD}_{(\mathrm{t})}$ concentration was measured as pmoles per mg protein based on a standard curve and expressed as \% change in PBBI vs. sham.

\section{$F A D_{(t)}$ Quantification}

Flavin Adenine Dinucleotide (FAD) is a coenzyme, synthesized from riboflavin, which plays critical roles in many metabolic pathways. FAD functions as an electron carrier in multiple redox reactions, cycling between $\mathrm{FAD}$ and $\mathrm{FADH}_{2}$. The primary sources of reduced FAD in eukaryotic metabolism are the TCA cycle and the beta oxidation reaction pathways. For total FAD or $\mathrm{FAD}_{(\mathrm{t})}$ (i.e., the combined form of both FAD and $\mathrm{FADH}_{2}$ ) content measurement, mitochondrial proteins $(100 \mu \mathrm{g})$ were resuspended in $100 \mu \mathrm{l}$ of FAD extraction buffer and deproteinizes with $8 \%$ perchloric acid solution. Briefly vortex and incubate the precipitate mixture for $5 \mathrm{~min}$. The mixture was centrifuged at $1,500 \times \mathrm{g}$ for $10 \mathrm{~min}$ and then transferred into a new tube for measurement $(50 \mu \mathrm{g} /$ well $)$. The $\mathrm{FAD}_{(\mathrm{t})}$ concentration was measured using fluorescence-based assay (Ex $\lambda 535$ and Em $\lambda 587 \mathrm{~nm}$ ) using commercially available FAD quantification kit (Sigma-Aldrich, USA). The $\mathrm{FAD}_{(\mathrm{t})}$ concentration were measured as pmoles per mg protein based on a standard curve and expressed as \% change in PBBI vs. sham.

\section{Statistical Analysis}

A priory power analyses were conducted to determine the sample size within individual experiments using $G^{*}$ Power 3
(Germany) statistical program. The power analyses based on previous mitochondrial bioenergetics data indicated that an $n$ $=5$ sample size/group, is sufficient to detect a $20 \%$ change as statistically significant $(p<0.05)$ with power of 0.8 compared to control. The experimental data are presented as bar graphs with error bars represented by \pm standard error of the mean (SEM). All mitochondrial samples were prepared from individual animals ( $n=5$ /group) using brain tissue derived from the cortex/striatum in the injured hemisphere. All samples were evaluated as triplicates in each experiment. An unpaired $t$-test was used for between-group comparisons (2 groups) whereas multiple group ( $>2$ groups) comparisons were conducted using analysis of variance (ANOVA) followed by a Fisher protected least squared differences (PLSD) post-hoc test (GraphPad Prism 6 software package, GraphPad Software, Inc. La Jolla, CA). Statistical significance was defined at ${ }^{*} p<0.05$.

\section{RESULTS}

Mitochondrial bioenergetics parameters were evaluated in brain samples that were pooled from the frontal cortex and striatum of the injured hemisphere. At $24 \mathrm{~h}$ post-PBBI, mitochondrial bioenergetics parameters (i.e., State II to State V respiration), mitochondrial dehydrogenase activities, and coenzyme contents were measured in the sham and PBBI groups. The schematic overview of brain mitochondrial metabolic reactions and bioenergetics (Figure 1A), and the real-time tracing of PMdriven mitochondrial respiration in $\mathrm{PBBI}$ vs. sham group were represented as illustrated (Figure 1B).

\section{Global Mitochondrial Bioenergetics Depression in PBBI}

At $24 \mathrm{~h}$ post-PBBI or sham injury, mitochondrial respiration rates were measured in the presence of glucose intermediate substrate sets: pyruvate+malate $(\mathrm{PM})$ and glutamate+malate (GM) (Figure 2). Following PBBI, mitochondrial respiration with PM showed a significant reduction in both State III (43\%, $\left.{ }^{*} p<0.05\right)$ and State V $\left(53 \%,{ }^{*} p<0.05\right)$ respiration. No change in PM driven basal respiration (State II) and proton leaks (State IV) were observed between the PBBI vs. sham groups (Figure 2A). Substrates GM showed similar trend in the PBBI group. Comparing to sham, the mitochondrial respiration with GM showed a trend toward altered State III respiration (42\%, $p=0.08$, non-significant), whereas State $\mathrm{V}$ respiration was reduced significantly $\left(62 \%,{ }^{*} p<0.05\right)$ in the PBBI group. No injury-induced changes were detected in GM driven basal respiration (State II) and proton leaks (State IV) (Figure 2B). Similarly, we evaluated mitochondrial bioenergetics parameters in the presence of two sets of additional glucose and ketone intermediates: succinate (Succ) and $\beta$-hydroxybutyrate+malate (BHBM) (Figure 3). When Succ was used as the metabolic substrate, both State III $\left(50 \%,{ }^{*} p<0.05\right)$ and State V $\left(40 \%,{ }^{*} p<\right.$ $0.05)$ respiration were significantly decreased in PBBI compared to sham. No change in Succ driven basal respiration (State II) and proton leaks (State IV) rates were observed between two groups (Figure 3A). With BHBM as substrates, the State III respiration 


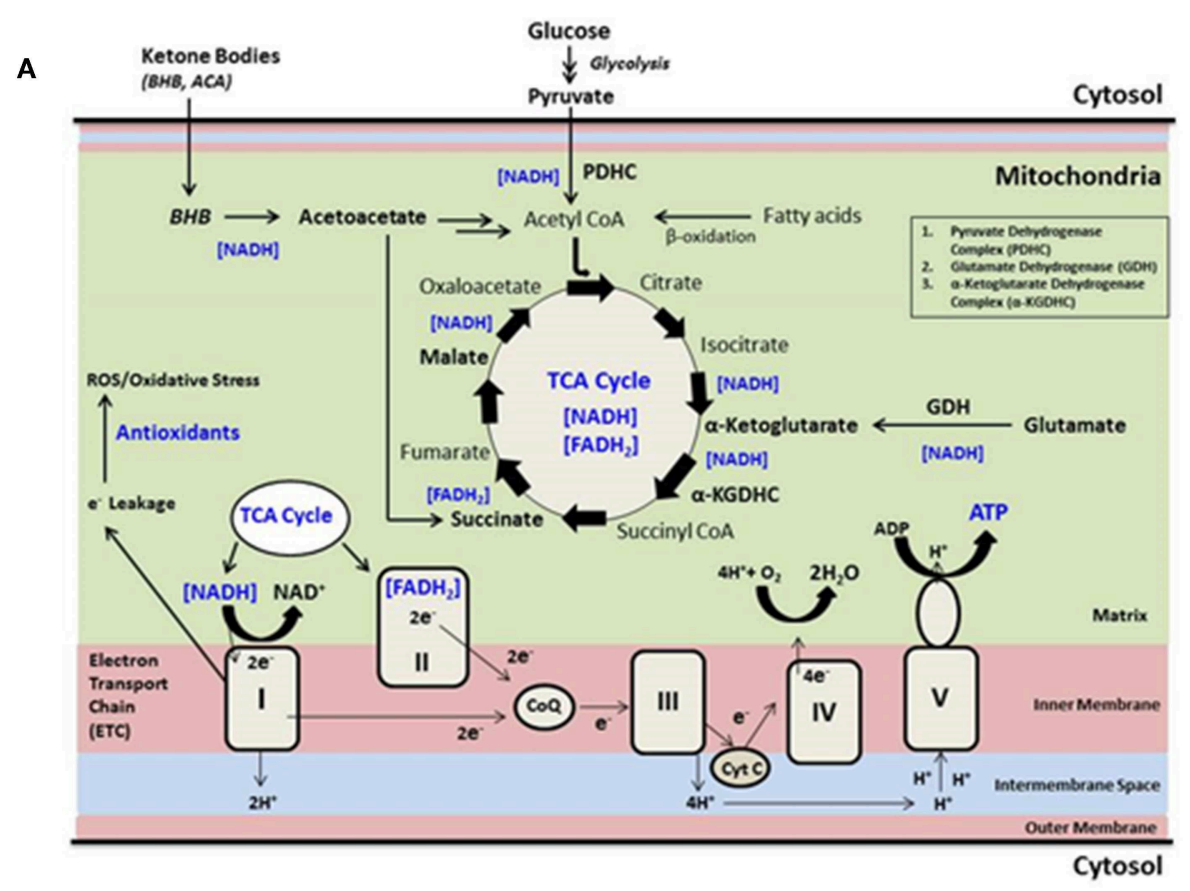

B

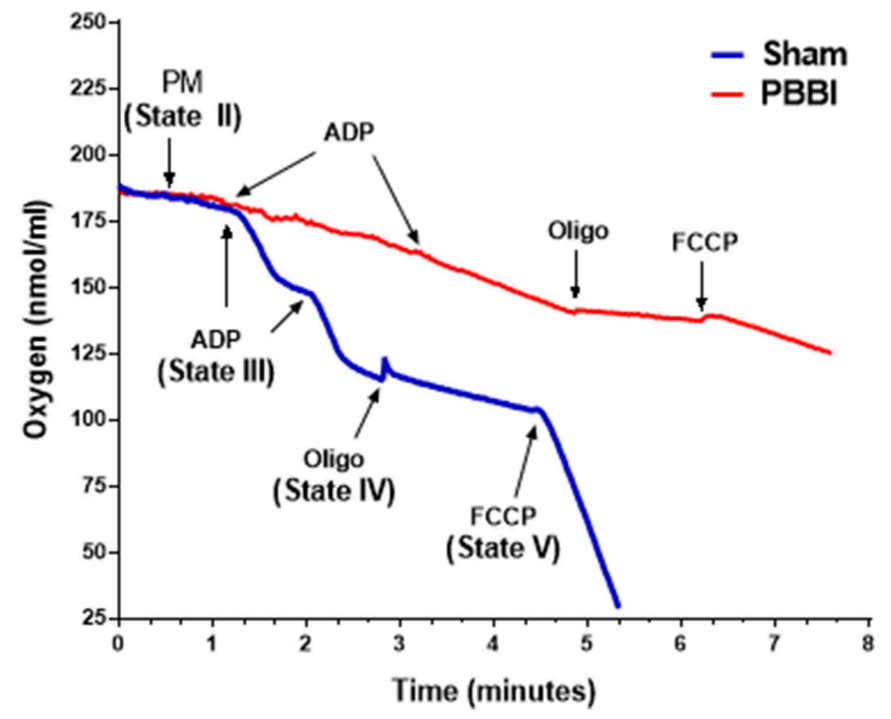

FIGURE 1 | Overview of mitochondrial respiration following PBBI. (A) As illustrated in the schematic, brain mitochondrial substrates (i.e., glucose and ketone intermediates) oxidation leads to ATP synthesis through coordinated metabolic reactions of mitochondrial enzymes. Glucose oxidation yield pyruvate through glycolysis, which may further converted to acetyl CoA by enzyme PDHC. Glutamate may oxidized to $\alpha$-Ketoglutarate by enzyme GDH. Ketone bodies (i.e., BHB or acetoacetate) may metabolized to acetyl CoA or Succinate. All brain energy metabolic substrates (i.e., pyruvate, glutamate, Succ, and BHB) oxidation increases the pool of reducing equivalents (i.e., NADH and FADH 2 ); and donates electrons to Complex I or II of ETC enzyme complexes, which triggers the flow of electrons down to the final accepter $\mathrm{O}_{2}$ to form $\mathrm{H}_{2} \mathrm{O}$ at Complex IV. Concomitantly, proton-pumping from matrix to the intermembrane space by mitochondrial ETC complexes I, III, and IV generates the mitochondrial membrane potential $(\Delta \Psi \mathrm{m})$. The $\Delta \Psi \mathrm{m}$ is then utilized to phosphorylate ADP to ATP through Complex V (i.e., ATP synthase). The complete oxidation of substrates in presence of $\mathrm{O}_{2}$ is linked with energy (i.e., ATP synthesis); therefore this process is termed as oxidative phosphorylation (OXPHOS). During OXPHOS, electron leaks ( 2\% electron leak) from mitochondrial ETC may generate reactive oxygen and nitrogen free radical species (i.e., ROS and RNS, respectively) and subsequent oxidative stress; which are counterbalanced by antioxidants in uninjured brain. (B) Representative traces PM-driven mitochondrial respiration in $\mathrm{PBBI}$ and sham groups. Briefly, incubate $50 \mu \mathrm{g}$ of mitochondrial protein into the sealed Clark-type oxygen electrode chamber containing KCl-based respiration buffer (Hansatech Instruments, England). In the real-time condition, sequentially add metabolic substrates/inhibitors of the mitochondrial respiration chain i.e., PM ( 1 min), ADP ( 2-3 min), oligomycin ( $4 \mathrm{~min})$, and FCCP ( $6 \mathrm{~min})$ to measure oxygen consumption rates (nmols/ml). The illustrated mitochondrial bioenergetics parameters a.k.a. State II respiration (i.e., basal respiration in presence of PM as the substrate set); State III respiration (ATP synthesis in presence of ADP); State IV respiration (i.e., proton leakage in presence of ETC complex $V$ inhibitor oligomycin); and State $V$ respiration (i.e., uncoupled respiration rates in presence of mitochondrial ETC uncoupler FCCP) were measured for each mitochondrial samples. Similarly, other mitochondrial substrates (i.e., GM, Succ, and BHBM) driven respiration rates were quantified separately. As noted here, the PBBI group (red trace) displayed reduced PM driven ATP synthesis (State III) and uncoupled respiration (State V) compared to sham (blue trace) group. 

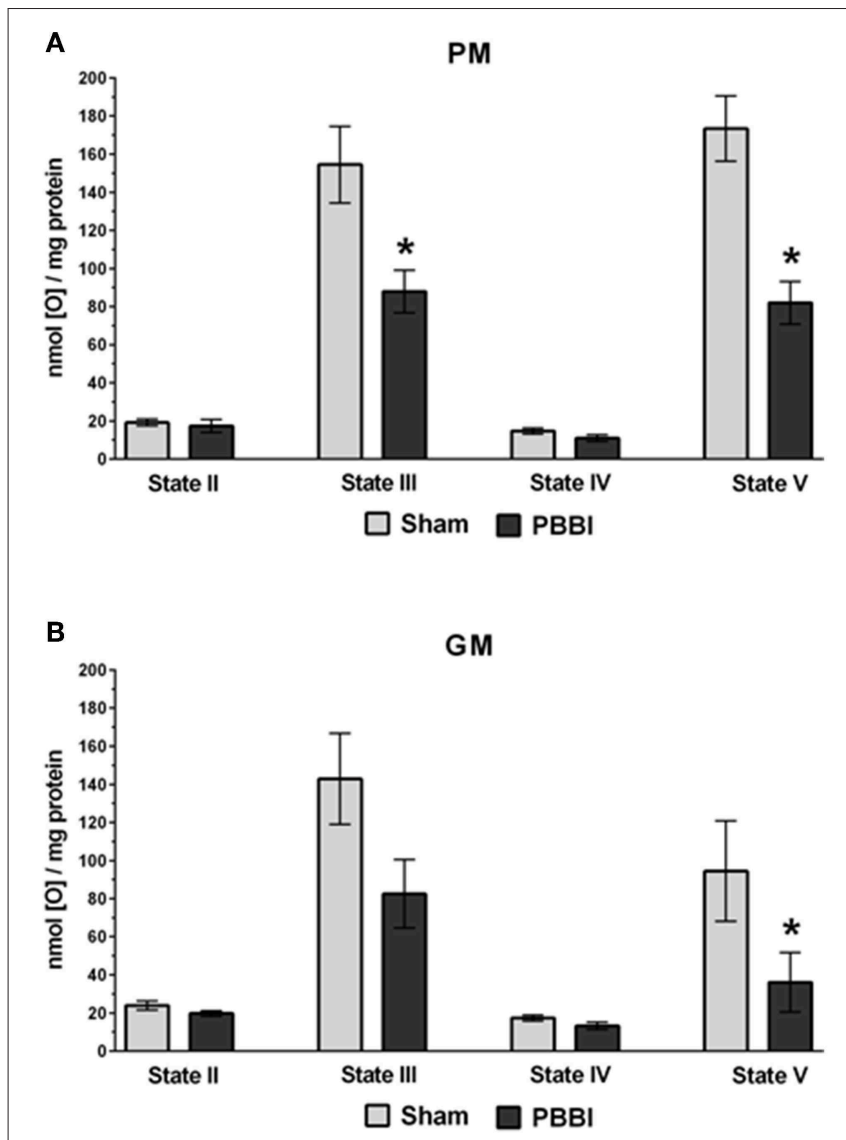

FIGURE 2 | Decreased ATP synthesis in the presence of metabolic substrates PM and GM following PBBI. (A,B) At $24 \mathrm{~h}$ post-PBBI or sham injury, mitochondrial respiration rates were measured using Clark-type oxygen electrode in the presence of metabolic substrates PM and GM. PBBI reduced ATP synthesis (State III) with PM $\left(43 \%,{ }^{*} p<0.05\right)$ and GM $(42 \%, p=0.08$ non-significant). No change in basal respiration (State II) and proton leaks (State IV) rates were observed. The FCCP induced uncoupling rates (State V) with PM and GM were significantly reduced in the PBBI group (53-62\%, ${ }^{*} p<$ 0.05). Bars represent group means \pm SEM ( $n=5$ animals / group). ${ }^{*} p<0.05$ compared to sham injured group (unpaired $t$-test). rate was reduced significantly $\left(43 \%,{ }^{*} p<0.05\right)$ in PBBI; whereas BHBM driven basal respiration (State II), proton leaks (State IV), and uncoupling rate (State $\mathrm{V}$ ) were comparable between the sham and PBBI groups (Figure 3B).

\section{Substrate Preference for ATP Synthesis}

To evaluate with-in group substrate preferences, the ATP synthesis rates of the four substrates were compared under either sham or PBBI condition (Figure 4). In the sham group, the PM, GM, and Succ substrate driven ATP synthesis (State III) were comparable; whereas the BHBM driven ATP synthesis was significantly lower compared to other substrates $\left(\mathrm{PM}=\mathrm{GM}=\right.$ Succ $\left.>\mathrm{BHBM},{ }^{*} p<0.05\right)$. In the PBBI group, the pattern of substrate utilization for ATP synthesis remained identical, but at a lower magnitude compared to the sham group. In the PBBI group, both PM and GM
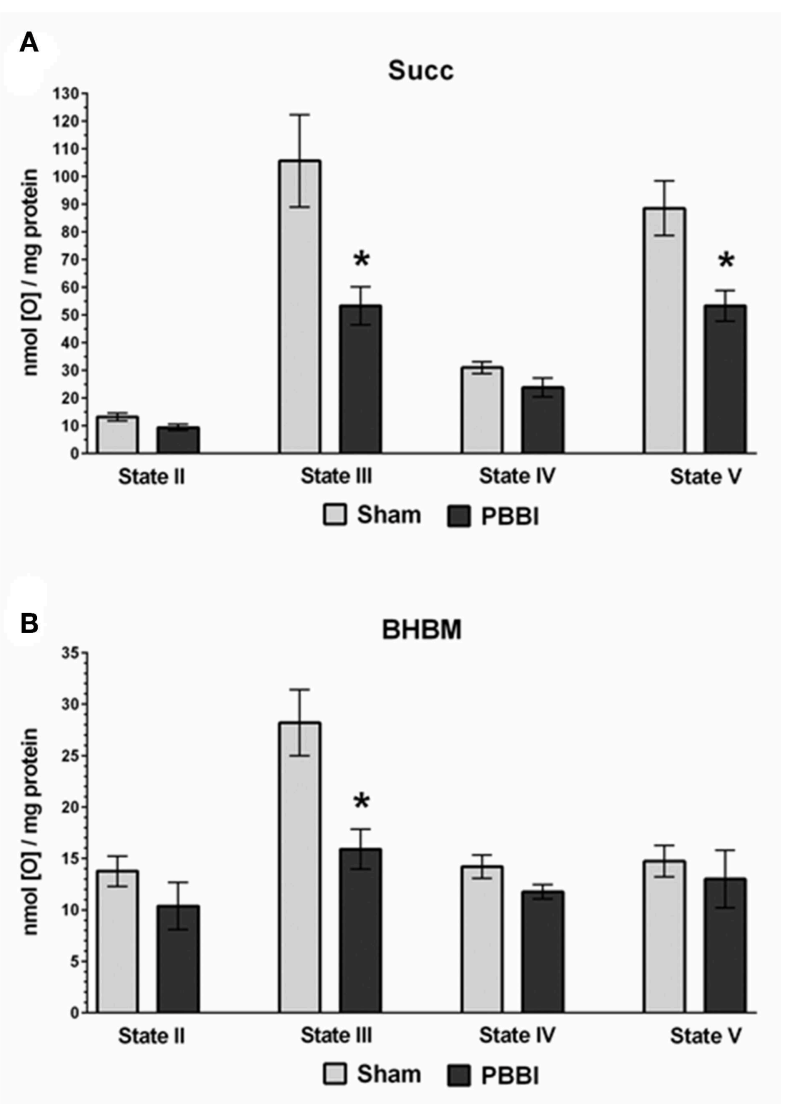

FIGURE 3 | Decreased ATP synthesis in the presence of metabolic substrates Succ and BHBM following PBBI. (A,B) At $24 \mathrm{~h}$ post-PBBI or sham injury, mitochondrial respiration rates were measured using Clark-type oxygen electrode in the presence of metabolic substrates succinate (Succ) and $\beta$-hydroxybutyrate+malate (BHBM). PBBI reduced the Complex II driven ATP synthesis (State III) with Succ $\left(50 \%,{ }^{*} p<0.05\right)$ and $\operatorname{BHBM}\left(43 \%,{ }^{*} p<0.05\right)$. No change in basal respiration (State II) and proton leaks (State IV) rates were observed. The FCCP induced uncoupling rates (State V) with Succ were significantly reduced in the PBBI group (40\%, $\left.{ }^{*} p<0.05\right)$. Bars represent group means \pm SEM ( $n=5$ animals / group). ${ }^{*} p<0.05$ compared to sham injured group (unpaired $t$-test).

driven ATP synthesis remained higher compared to that driven by Succ and BHBM. The ATP synthesis between PM, Succ, and $\mathrm{BHBM}$ were significantly distinct amongst each other $\left(\mathrm{PM}=\mathrm{GM}>\right.$ Succ $>$ BHBM,$\left.{ }^{*} p<0.05\right)$.

\section{Mitochondrial Dehydrogenase Enzyme Activities in PBBI}

Mitochondrial matrix dehydrogenases, $\mathrm{PDHC}$ and $\mathrm{GDH}$ activities were significantly decreased compared to the sham group (42 and 53\%, respectively, ${ }^{*} p<0.05$ ). No injury-specific differences were detected in the $\alpha$-KGDHC activity between PBBI and sham groups (Figure 5A). In the PBBI group, mitochondrial membrane-bound dehydrogenases, Complex I and Complex IV enzyme activities were significantly decreased compared to the sham group (47 and $81 \%$, respectively, ${ }^{*} p<0.05$ ); 


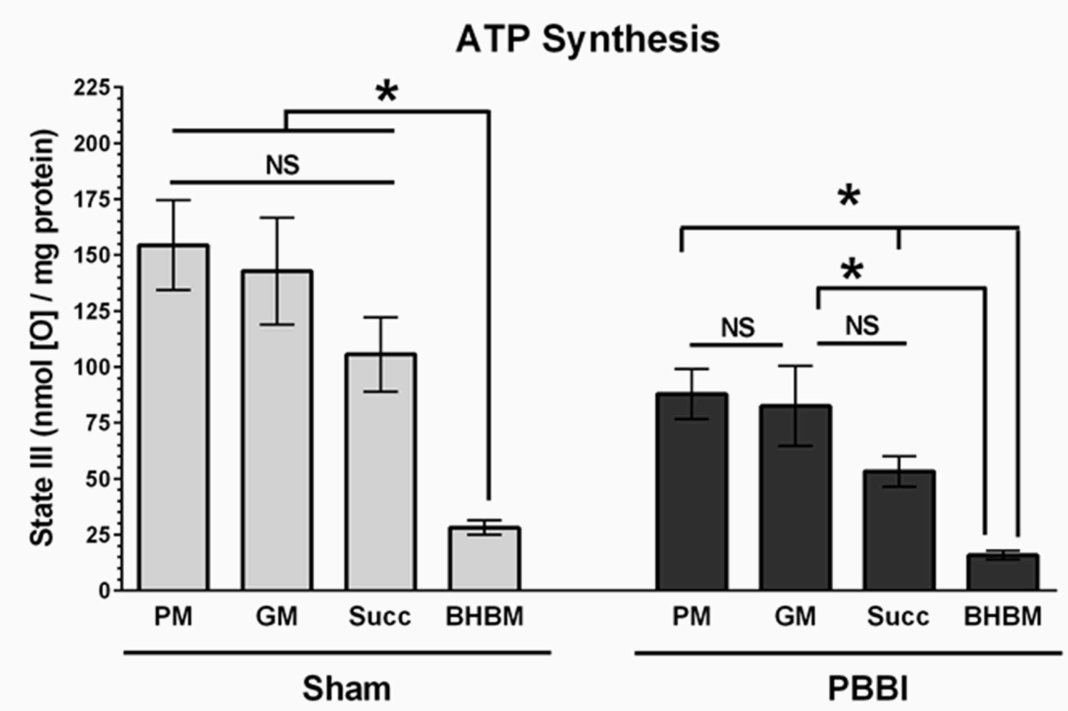

FIGURE 4 | Comparison of ATP synthesis rates with-in the experimental group. The ATP synthesis rates of the four substrates (i.e., PM, GM, Succ, and BHBM) were compared with-in sham or PBBI group. In the sham group, the BHBM showed significantly less ATP synthesis than any other substrates (PM=GM=Succ $>$ BHBM, ${ }^{*} P$ $<0.05)$. In the PBBI group, the ATP synthesis of PM, Succ, and BHBM were significantly distinct amongst each other (PM=GM $>$ Succ $>$ BHBM, $\left.{ }^{\star} p<0.05\right)$. Bars represent group means \pm SEM ( $n=5$ animals / group). ${ }^{*} p<0.05$ compared within four substrates groups of sham or PBBI (ANOVA, Fisher post-hoc test).

whereas Complex II activity was comparable to that in the sham group (Figure 5B).

\section{Decreased Coenzyme Contents in PBBI}

Mitochondrial coenzyme contents (i.e., $\mathrm{NAD}_{(\mathrm{t})}$ and $\mathrm{FAD}_{(\mathrm{t})}$ ) were quantitatively measured in $\mathrm{PBBI}$ and sham groups. In the PBBI group, both $\mathrm{NAD}_{(\mathrm{t})}\left(35 \%,{ }^{*} p<0.05\right)$ and $\mathrm{FAD}_{(\mathrm{t})}$ contents $(27 \%$, $\left.{ }^{*} p<0.05\right)$ were significantly decreased compared to the sham group (Figure 6).

\section{DISCUSSION}

The uninjured healthy brain preferentially utilizes glucose intermediates (vs. ketones) as the primary and obligated source of energy-rich metabolic fuels (35). Our previous research revealed significant alterations in metabolic responses between $30 \mathrm{~min}$ and $7 \mathrm{~d}$ post-PBBI, including osmotic stress, neurotransmitters imbalance, hyper-glycolysis, decreased TCA cycle anaplerotic metabolism, depletion of creatine stores, and enhanced complex lipid hydrolysis (36). We also detected altered glucose uptake and oxygen consumption in the injured cortex, including both the injury core and the peri-lesional area, at $2.5 \mathrm{~h}$ post-PBBI (37). In addition, using intracerebral microdialysis, we have reported an early energy metabolic dysfunction and the metabolic shift toward anaerobic glycolysis (indicated by high lactate to pyruvate ratio) within $3 \mathrm{~h}$ following PBBI (38).

The current study was designed to examine the acute brain mitochondrial bioenergetics dysfunction following PBBI based on our previous observations of the cerebral metabolomics alterations in this brain injury model. Results of the current study demonstrate mitochondrial bioenergetics failure evident at $24 \mathrm{~h}$ post-PBBI, which was likely due to a global declines in substrate utilization for energy production, including altered mitochondrial dehydrogenase activities and coenzyme contents. These results correspond with and build on previous work conducted in the CCI model of TBI $(16,34,39-44)$. In the CCI model, the majority of published studies have utilized only pyruvate + malate $(\mathrm{PM})$ as the energy substrates to evaluate Complex I driven mitochondrial respiration, in which the PM dependent mitochondrial ATP synthesis rates were significantly reduced within $30 \mathrm{~min}$ post-injury (39) and remain compromised up to 2-5 d post-injury (40-42). However, Xiong et al. reported that glutamate+malate (GM) dependent Complex I driven mitochondrial ATP synthesis was decreased between $1 \mathrm{~h}$ and $14 \mathrm{~d}$ post-injury (43). In the current study, we evaluated both $\mathrm{PM}$ and GM as metabolic substrates for complex I driven mitochondrial respiration in the PBBI model. Our results showed a reduction in both complex I driven ATP synthesis rates (State III) and uncoupling rates (State V) following PBBI (Figure 2). Notably, we had previously hypothesized that the reduction in PM driven ATP synthesis may be counterbalanced by the use of GM as an alternative metabolic substrate to produce ATP following PBBI, based early evidence that showed elevated extracellular glutamate levels following TBI (45-47). However, results from the current study showed a GM-dependent nonsignificant decrease trend in ATP synthesis following PBBI, which indirectly suggests that the glutamate substrate may not be an efficient alternative fuel for energy replenishment following PBBI. 


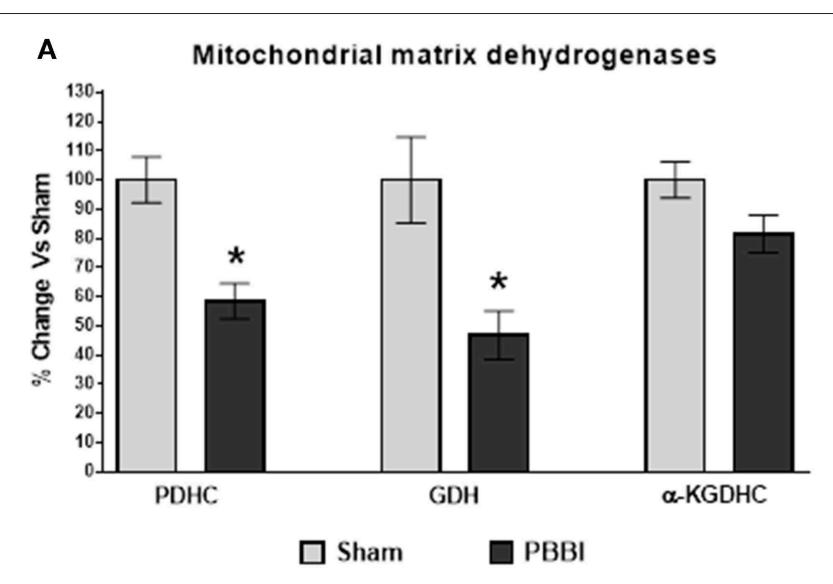

B Mitochondrial membrane-bound dehydrogenases

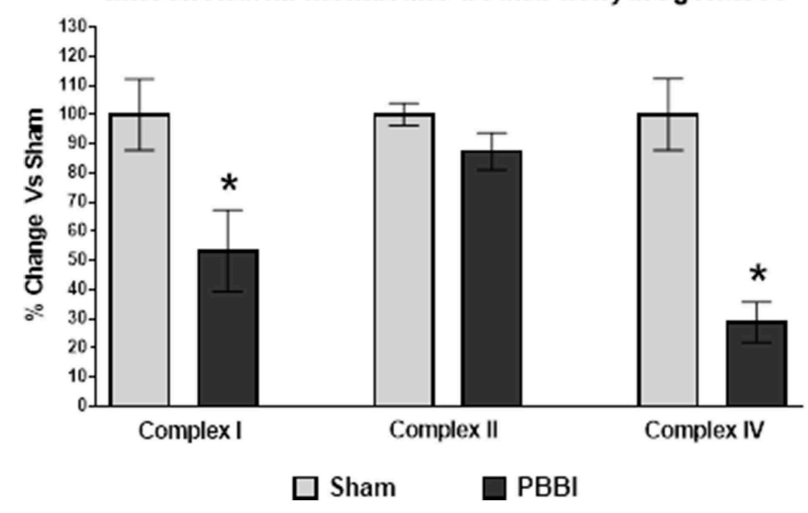

FIGURE 5 | Decreased dehydrogenase activities following PBBI. (A) At $24 \mathrm{~h}$ post-PBBI, PDHC $(42 \%, p<0.05)$ and GDH $(53 \%, p<0.05)$ enzyme activities were significantly decreased; whereas no significant differences were noted in $\alpha$-KGDHC activity between groups. (B) The Complex I (47\%, ${ }^{*} p<$ $0.05)$ and Complex IV $\left(81 \%,{ }^{*} p<0.05\right)$ enzyme activities of ETC were significantly impaired in the PBBI group; whereas no change in Complex II enzyme activity was observed between experimental groups. Bars represent group means \pm SEM ( $n=5$ animals / group). ${ }^{*} p<0.05$ compared to sham injured group (unpaired $t$-test).

We used two additional glucose and ketone intermediate substrates, succinate (Succ), and beta-hydroxybutyrate+malate (BHBM), to evaluate their bioenergetics capacity in the PBBI model (Figure 3). Both of these substrates support Complex II driven mitochondrial respiration for ATP synthesis, and thereby may bypass the Complex I driven respiration and partially circumvent the dependence on both PDHC and Complex I enzyme functions. It was reported that both PDHC and Complex I enzyme activities were significantly decreased at $3 \mathrm{~h}$ post-injury following CCI (34). To evaluate whether the Complex II driven respiration is also compromised, the Succ and BHBM dependent mitochondrial ATP synthesis rates were measured in isolated mitochondria following TBI. The results showed that both Succ and BHBM dependent ATP synthesis were significantly decreased following PBBI, which indicates that Complex II driven energy production were significantly compromised. Together, a significant decline in both Complex
I and II driven ATP synthesis rates indicated global metabolic depression following PBBI. As such, this global energy crisis might potentially be mitigated using energy enhancers as a therapeutic treatment for acute TBI.

In support of this hypothesis, recent efforts were carried out to potentiate brain energy metabolism using alternative energy substrates in TBI patients. In one such study, Jalloh et al. reported that the ${ }^{13} \mathrm{C}$-labeled succinate $(12 \mathrm{mmol} / \mathrm{L}$ for $24 \mathrm{~h})$ perfused via intracerebral catheter decreased the lactate/pyruvate ratio measured in microdialysate samples, and improved glucose and glutamate utilization, thereby favoring aerobic glycolysis through metabolic flux into the TCA cycle in nine TBI patients with Glasgow Coma Scale $\leq 8$ (48). These results provide support for the use of TCA cycle products or alternative energy substrates for enhancing brain mitochondrial metabolism in TBI patients as previously suggested (49-56).

In the current study, substrate dependent ATP synthesis rates were compared among major energy intermediates (i.e., pyruvate, glutamate, succinate and $\beta$-hydroxybutyrate) to identify the mitochondria preferred energy substrates at $24 \mathrm{~h}$ following either sham or PBBI procedure (Figure 4). Under the sham condition, the ATP synthesis rate of PM, GM, and Succ were unchanged amongst each other and were all significantly higher than that of BHBM $(\mathrm{PM}=\mathrm{GM}=$ Succ $>\mathrm{BHBM})$. Similarly, Berg et al. observed that the uninjured healthy brain mitochondria preferred glucose intermediates over ketones as energy substitutes and the metabolic responses were tissue-specific (35). In the current study, it was postulated that the metabolic substrates preference for energy production may have changed due to incurred metabolic stress following PBBI. Interestingly, our results showed that under the PBBI condition, $\mathrm{PM}$ and $\mathrm{GM}$ remained as preferred substrates for the injured brain, while the ketone BHBM utilization remained as the lowest compared to other glucose intermediates $(\mathrm{PM}=\mathrm{GM}>$ Succ $>\mathrm{BHBM})$. This is the first time that global metabolic substrate utilization pattern for ATP synthesis was evaluated in ex vivo condition following TBI. Overall, our results showed that glucose intermediate substrate utilization was declined following injury and ketone utilization remained the lowest when tested in ex vivo condition using isolated mitochondria from the PBBI brains.

All four metabolic substrates tested here for ATP synthesis showed energy deficits at $24 \mathrm{~h}$ post-PBBI, suggesting that therapeutic treatments should be initiated as early as possible to mitigate secondary injury responses of energy crisis following PBBI. Additionally, it may possible that these mitochondrial energy dysfunctions persist upto $2-5 \mathrm{~d}$ post-PBBI, as observed in the CCI model $(40,41)$. Similar to the current energy deficits observed at the injury core and peri-lesional brain regions (i.e., frontal cortex and striatum), the other brain regions which are distant to the injury site may show mitochondrial bioenergetics impairments. Therefore, a comprehensive postinjury time-course analysis of mitochondrial bioenergetics from different brain regions are warranted to better understand the brain region-specific injury responses following PBBI.

Several mitochondrial proteins involved in the cellular bioenergetics displayed oxidative modification following TBI. 
A proteomics study carried out by Opii et al. observed that mitochondrial dehydrogenase activities were reduced at $3 \mathrm{~h}$ post-CCI and several mitochondrial proteins displayed oxidative damage following TBI (34). In the current study, we measured mitochondrial dehydrogenase activities at $24 \mathrm{~h}$ post-PBBI (Figure 5). The mitochondrial matrix dehydrogenase (i.e., PDHC and GDH) activities were significantly reduced following PBBI, whereas the $\alpha-\mathrm{KGDHC}$ activity was comparable between the sham and PBBI groups. The reduced PDHC and GDH enzyme activities may affect the PM and GM dependent ATP synthesis rates in the PBBI group as discussed previously. Moreover, the mitochondrial membrane-bound dehydrogenase Complex I and IV activities were significantly decreased after PBBI. In contrast, Complex II enzyme activity was not affected following PBBI. Originally, it was postulated that mitochondrial dehydrogenase activities would drop significantly due to the observed global decline in energy metabolism indicated by ATP synthesis and coenzyme $\left(\mathrm{NAD}_{\mathrm{t}}\right.$ and $\left.\mathrm{FAD}_{\mathrm{t}}\right)$ contents following PBBI. However, it is counterintuitive that both $\alpha-\mathrm{KGDHC}$ and Complex II enzyme activities remained unchanged despite of their cofactors' levels were significantly lower following PBBI. Overall, these data suggest the differential susceptibility of mitochondrial dehydrogenase activities to secondary injury, possibly due to the divergent redox-state sensitivity within their structures, ultimately leading to altered substrates oxidation, metabolic suppression, and energy depletion following injury. However, this hypothesis warrants further evaluation to confirm the causative effects of mitochondrial enzyme oxidation on the post-injury energy metabolism.

The use of Complex II driven energy substrates such as succinate or ketones, which oxidation feed electrons through Complex II, would be a good choice as "alternative biofuels," given that they bypass the enzymatic dysfunction of both PDHC and Complex $\mathrm{I}$ in OXPHOS following PBBI. In the literature, pro-drugs that serve as alternativeenergy substrates have been evaluated, glyceryl triacetate, or acetyl L-carnitine, which may bypass mitochondrial PDHC deficiency following brain and spinal cord injuries (12, 54, 55, 57-59). Similarly, decreases in PDHC and Complex I enzyme activities following PBBI observed here may be bypassed by the utilization of complex II driven alternative energy fuels for severe penetrating brain trauma. Note that the Complex IV enzyme activity was severely reduced following PBBI, consistent with previous findings in the CCI model (34). As Complex IV is the terminal enzyme complex of the ETC oxidative phosphorylation, any therapeutic intervention discussed above designed to bypass PDHC and Complex I enzymes may not be exclusively efficient to overcome complex IV deficiency. Therefore, drug intervention that can prevent or delay damage to Complex IV enzyme may prove beneficial for therapeutic purposes in combination with alternative biofuels/drugs to increase ATP synthesis following injury. Comprehensively, the current study has evaluated several mitochondrial targets, which can be bypassed / protected individually or in combination in the future using therapeutic interventions to alleviate metabolic depression following severe penetrating TBI.

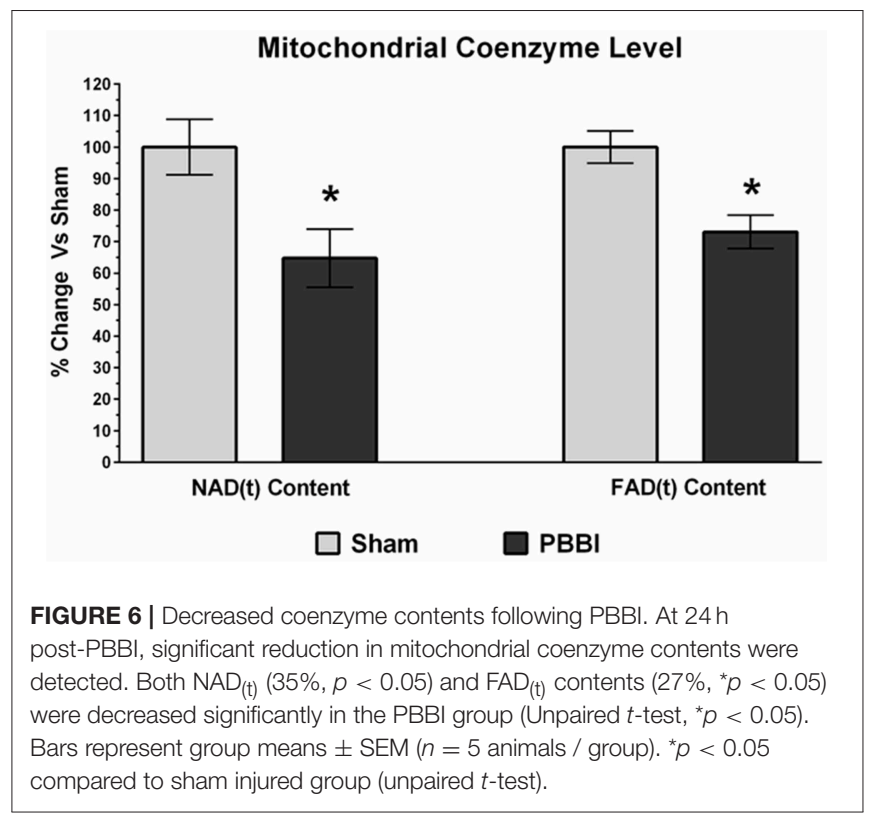

In the current study, we measured both $\mathrm{NAD}_{(\mathrm{t})}$ and $\mathrm{FAD}_{(\mathrm{t})}$ contents using biochemical assays. These cofactors play essential roles in many cellular and mitochondria specific metabolic reactions by acting as electron $\left(\mathrm{e}^{-}\right)$and proton $\left(\mathrm{H}^{+}\right)$donors for substrate oxidation. In the mitochondrial ETC chain, the $\mathrm{NADH}$ transfers electrons to Complex I, whereas the FAD is a prosthetic group of Complex II which receives electrons from succinate, thereby bypassing Complex I for ATP synthesis. Our data presented here (Figure 6) showed a significant decline in both $\mathrm{NAD}_{(\mathrm{t})}$ and $\mathrm{FAD}_{(\mathrm{t})}$ contents following PBBI, which indicated that the capability to carry out efficient electron and proton transfers for ATP synthesis remained limited. Therefore, therapeutics that target replenishment of $\mathrm{NAD}_{(\mathrm{t})}$ and $\mathrm{FAD}_{(\mathrm{t})}$ may be useful in combination with Complex IV agonists to enhance energy efficiency following severe TBI. Efforts toward evaluating NAD and its precursors, nicotinamide and nicotinic acid, as neuroprotective agents for TBI and ischemic brain injury have shown some improvement in behavioral functions (60-68). However, more rigorous efforts are needed to validate bioenergetics and neuroprotective efficacy of both NAD and FAD precursors as a treatment for TBI.

In summary, our study provided a comprehensive evaluation of mitochondrial dysfunction at $24 \mathrm{~h}$ following PBBI. We observed glucose or ketone intermediate substrates mediated decline in ATP synthesis following PBBI. Additionally, mitochondrial dehydrogenase activities and coenzyme contents were significantly decreased following PBBI. While additional experiments are warranted to provide a comprehensive time-course and injury severity profile of mitochondrial bioenergetics in the PBBI model, the results of the current study provide a basis for the use of "alternative biofuels" for achieving higher ATP production following severe penetrating brain trauma. 


\section{ETHICS STATEMENT}

All experimental procedures were approved by the Institutional Animal Care and Use Committee (IACUC) at Walter Reed Army Institute of Research (WRAIR). Animal studies were conducted in compliance with the Animal Welfare Act, the Guide for the Care and Use of Laboratory Animals (National Research Council), and other federal statutes and regulations relating to animals and experiments involving animals.

\section{AUTHOR CONTRIBUTIONS}

JP contributed in literature review, research experiments, data analysis, and manuscript writing. $\mathrm{XY}$ and

\section{REFERENCES}

1. Bergsneider M, Hovda DA, Lee SM, Kelly DF, McArthur DL, Vespa PM, et al. Dissociation of cerebral glucose metabolism and level of consciousness during the period of metabolic depression following human traumatic brain injury. $J$ Neurotrauma. (2000) 17:389-401. doi: 10.1089/neu.2000.17.389

2. Hovda DA, Yoshino A, Kawamata T, Katayama Y, Becker DP. Diffuse prolonged depression of cerebral oxidative metabolism following concussive brain injury in the rat: a cytochrome oxidase histochemistry study. Brain Res. (1991) 567:1-10. doi: 10.1016/0006-8993(91)91429-5

3. Sunami K, Nakamura T, Ozawa Y, Kubota M, Namba H, Yamaura A. Hypermetabolic state following experimental head injury. Neurosurg Rev. (1989) 12(Suppl. 1):400-11. doi: 10.1007/BF01790682

4. Werner C, Engelhard K. Pathophysiology of traumatic brain injury. $\mathrm{Br} J$ Anaesth. (2007) 99:4-9. doi: 10.1093/bja/aem131

5. Sutton RL, Hovda DA, Adelson PD, Benzel EC, Becker DP. Metabolic changes following cortical contusion: relationships to edema and morphological changes. Acta Neurochir Suppl. (1994) 60:446-8. doi: 10.1007/978-3-7091-9334-1_122

6. Bergsneider M, Hovda DA, Shalmon E, Kelly DF, Vespa PM, Martin NA, et al. Cerebral hyperglycolysis following severe traumatic brain injury in humans: a positron emission tomography study. J Neurosurg. (1997) 86:24151. doi: 10.3171/jns.1997.86.2.0241

7. O'Connell MT, Seal A, Nortje J, Al-Rawi PG, Coles JP, Fryer TD, et al. Glucose metabolism in traumatic brain injury: a combined microdialysis and [18F]-2fluoro-2-deoxy-D-glucose-positron emission tomography (FDG-PET) study. Acta Neurochir Suppl. (2005) 95:165-8. doi: 10.1007/3-211-32318-X_35

8. Yoshino A, Hovda DA, Kawamata T, Katayama Y, Becker DP. Dynamic changes in local cerebral glucose utilization following cerebral conclusion in rats: evidence of a hyper- and subsequent hypometabolic state. Brain Res. (1991) 561:106-19. doi: 10.1016/0006-8993(91)90755-K

9. Deng-Bryant Y, Prins ML, Hovda DA, Harris NG. Ketogenic diet prevents alterations in brain metabolism in young but not adult rats after traumatic brain injury. J Neurotrauma. (2011) 28:1813-25. doi: 10.1089/neu.2011.1822

10. Alessandri B, Reinert M, Young HF, Bullock R. Low extracellular (ECF) glucose affects the neurochemical profile in severe head-injured patients. Acta Neurochir Suppl. (2000) 76:425-30. doi: 10.1007/978-3-7091-6346-7_88

11. Goodman JC, Valadka AB, Gopinath SP, Uzura M, Robertson CS. Extracellular lactate and glucose alterations in the brain after head injury measured by microdialysis. Crit Care Med. (1999) 27:1965-73. doi: 10.1097/00003246-199909000-00041

12. Scafidi S, Racz J, Hazelton J, McKenna MC, Fiskum G. Neuroprotection by acetyl-L-carnitine after traumatic injury to the immature rat brain. Dev Neurosci. (2010) 32:480-7. doi: 10.1159/000323178

13. IOM (2011). IOM (Institute of Medicine). Nutrition and Traumatic Brain Injury: Improving Acute and Subacute Health Outcomes in Military Personnel. Washington, DC: The National Academies Press.
WF provided technical assistance. LL, YD-B, JG, and DS participated in experimental design and manuscript writing.

\section{FUNDING}

Material has been reviewed by WRAIR. There is no objection to its presentation and/or publication. The opinions or assertions contained herein are the private views of the authors and are not to be construed as official, or as reflecting true views of the Department of the Army of the Department of Defense. Support: US Army Combat Casualty Care Research Program H_026_2014_WRAIR and H_001_2018_WRAIR.

14. Perel P, Yanagawa T, Bunn F, Roberts I, Wentz R, Pierro A. Nutritional support for head-injured patients. Cochrane Database Syst Rev. (2006) 4:CD001530. doi: 10.1002/14651858.CD001530.pub2

15. Yanagawa T, Bunn F, Roberts I, Wentz R, Pierro A. Nutritional support for head-injured patients. Cochrane Database Syst Rev. (2002) 3:CD001530. doi: 10.1002/14651858.CD001530

16. Pandya JD, Pauly JR, Nukala VN, Sebastian AH, Day KM, Korde AS, et al. Post-injury administration of mitochondrial uncouplers increases tissue sparing and improves behavioral outcome following traumatic brain injury in rodents. J Neurotrauma. (2007) 24:798-811. doi: 10.1089/neu.2006.3673

17. Sullivan PG, Rabchevsky AG, Waldmeier PC, Springer JE. Mitochondrial permeability transition in CNS trauma: cause or effect of neuronal cell death? J Neurosci Res. (2005) 79:231-9. doi: 10.1002/jnr.20292

18. Yonutas HM, Vekaria HJ, Sullivan PG. Mitochondrial specific therapeutic targets following brain injury. Brain Res. (2016) 1640(Pt A):77-93. doi: 10.1016/j.brainres.2016.02.007

19. Bains M, Hall ED. Antioxidant therapies in traumatic brain and spinal cord injury. Biochim Biophys Acta. (2012) 1822:675-84. doi: 10.1016/j.bbadis.2011.10.017

20. Hall ED, Vaishnav RA, Mustafa AG. Antioxidant therapies for traumatic brain injury. Neurotherapeutics. (2010) 7:51-61. doi: 10.1016/j.nurt.2009.10.021

21. Crompton M. The mitochondrial permeability transition pore and its role in cell death. Biochem J. (1999) 341(Pt 2):233-49. doi: 10.1042/bj3410233

22. Halestrap AP. Mitochondrial calcium in health and disease. Biochim Biophys Acta. (2009) 1787:1289-90. doi: 10.1016/j.bbabio.2009.07.011

23. Halestrap AP. What is the mitochondrial permeability transition pore? J Mol Cell Cardiol. (2009) 46:821-31. doi: 10.1016/j.yjmcc.2009.02.021

24. Shear DA, Lu XC, Bombard MC, Pedersen R, Chen Z, Davis A, et al. Longitudinal characterization of motor and cognitive deficits in a model of penetrating ballistic-like brain injury. J Neurotrauma. (2010) 27:1911-23. doi: 10.1089/neu.2010.1399

25. Shear DA, Lu XC, Pedersen R, Wei G, Chen Z, Davis A, et al. Severity profile of penetrating ballistic-like brain injury on neurofunctional outcome, bloodbrain barrier permeability, and brain edema formation. J Neurotrauma. (2011) 28:2185-95. doi: 10.1089/neu.2011.1916

26. Williams AJ, Hartings JA, Lu XC, Rolli ML, Dave JR, Tortella FC. Characterization of a new rat model of penetrating ballistic brain injury. $J$ Neurotrauma. (2005) 22:313-31. doi: 10.1089/neu.2005.22.313

27. Pandya JD, Grondin R, Yonutas HM, Haghnazar H, Gash DM, Zhang $Z$, et al. Decreased mitochondrial bioenergetics and calcium buffering capacity in the basal ganglia correlates with motor deficits in a nonhuman primate model of aging. Neurobiol Aging. (2015) 36:1903-13. doi: 10.1016/j.neurobiolaging.2015.01.018

28. Pandya JD, Sullivan PG, Leung LY, Tortella FC, Shear DA, Deng-Bryant Y. Advanced and high-throughput method for mitochondrial bioenergetics evaluation in neurotrauma. Methods Mol Biol. (2016) 1462:597-610. doi: 10.1007/978-1-4939-3816-2_32 
29. Sullivan PG, Krishnamurthy S, Patel SP, Pandya JD, Rabchevsky AG. Temporal characterization of mitochondrial bioenergetics after spinal cord injury. J Neurotrauma. (2007) 24:991-9. doi: 10.1089/neu.2006.0242

30. Gash DM, Rutland K, Hudson NL, Sullivan PG, Bing G, Cass WA, et al. Trichloroethylene: parkinsonism and complex 1 mitochondrial neurotoxicity. Ann Neurol. (2008) 63:184-92. doi: 10.1002/ana.21288

31. Pandya JD, Readnower RD, Patel SP, Yonutas HM, Pauly JR, Goldstein GA, et al. $\mathrm{N}$-acetylcysteine amide confers neuroprotection, improves bioenergetics and behavioral outcome following TBI. Exp Neurol. (2014) 257:106-13. doi: 10.1016/j.expneurol.2014.04.020

32. Pandya JD, Royland JE, MacPhail RC, Sullivan PG, Kodavanti PR. Age- and brain region-specific differences in mitochondrial bioenergetics in Brown Norway rats. Neurobiol Aging. (2016) 42:25-34. doi: 10.1016/j.neurobiolaging.2016.02.027

33. Patel SP, Sullivan PG, Pandya JD, Goldstein GA, VanRooyen JL, Yonutas $\mathrm{HM}$, et al. $\mathrm{N}$-acetylcysteine amide preserves mitochondrial bioenergetics and improves functional recovery following spinal trauma. Exp Neurol. (2014) 257:95-105. doi: 10.1016/j.expneurol.2014.04.026

34. Opii WO, Nukala VN, Sultana R, Pandya JD, Day KM, Merchant ML, et al. Proteomic identification of oxidized mitochondrial proteins following experimental traumatic brain injury. J Neurotrauma. (2007) 24:772-89. doi: 10.1089/neu.2006.0229

35. Berg JM, Tymoczko J, Stryer L. Biochemistry. 5th edition. New York, NY: W. H., and Freeman; 2002. Section 30.2, Each Organ Has a Unique Metabolic Profile (2002). Available online at: https://www.ncbi.nlm.nih.gov/ books/NBK22436/

36. Deng-Bryant Y, Leung LY, Pandya JD, Yang W, Gilsdorf J, Shear DA. Global metabolomics analysis in rats following penetrating ballistic-like brain injury. J Neurotrauma. (2016) 33:A54.

37. Gajavelli S, Kentaro S, Diaz J, Yokobori S, Spurlock M, Diaz D, et al. Glucose and oxygen metabolism after penetrating ballistic-like brain injury. J Cereb Blood Flow Metab. (2015) 35:773-80. doi: 10.1038/jcbfm.2014.243

38. Leung LY, Deng-Bryant Y, Cardiff K, Winter M, Tortella F, Shear D. Neurochemical changes following combined hypoxemia and hemorrhagic shock in a rat model of penetrating ballistic-like brain injury: a microdialysis study. J Trauma Acute Care Surg. (2016) 81:860-7. doi: 10.1097/TA.0000000000001206

39. Gilmer LK, Roberts KN, Joy K, Sullivan PG, Scheff SW. Early mitochondrial dysfunction after cortical contusion injury. J Neurotrauma. (2009) 26:127180. doi: $10.1089 /$ neu.2008.0857

40. Hill RL, Singh IN, Wang JA, Hall ED. Time courses of post-injury mitochondrial oxidative damage and respiratory dysfunction and neuronal cytoskeletal degradation in a rat model of focal traumatic brain injury. Neurochem Int. (2017) 111:45-56. doi: 10.1016/j.neuint.2017. 03.015

41. Singh IN, Sullivan PG, Deng Y, Mbye LH, Hall ED. Time course of posttraumatic mitochondrial oxidative damage and dysfunction in a mouse model of focal traumatic brain injury: implications for neuroprotective therapy. J Cereb Blood Flow Metab. (2006) 26:1407-18. doi: 10.1038/sj.jcbfm. 9600297

42. Pandya JD, Pauly JR, Sullivan PG. The optimal dosage and window of opportunity to maintain mitochondrial homeostasis following traumatic brain injury using the uncoupler FCCP. Exp Neurol. (2009) 218:381-9. doi: 10.1016/j.expneurol.2009.05.023

43. Xiong Y, Gu Q, Peterson PL, Muizelaar JP, Lee CP. Mitochondrial dysfunction and calcium perturbation induced by traumatic brain injury. J Neurotrauma. (1997) 14:23-34. doi: 10.1089/neu.1997.14.23

44. Kilbaugh TJ, Karlsson M, Byro M, Bebee A, Ralston J, Sullivan S, et al. Mitochondrial bioenergetic alterations after focal traumatic brain injury in the immature brain. Exp Neurol. (2015) 271:136-44. doi: 10.1016/j.expneurol.2015.05.009

45. Baker AJ, Moulton RJ, MacMillan VH, Shedden PM. Excitatory amino acids in cerebrospinal fluid following traumatic brain injury in humans. J Neurosurg. (1993) 79:369-72. doi: 10.3171/jns.1993.79.3.0369

46. Chamoun R, Suki D, Gopinath SP, Goodman JC, Robertson C. Role of extracellular glutamate measured by cerebral microdialysis in severe traumatic brain injury. J Neurosurg. (2010) 113:564-70. doi: 10.3171/2009.12.JNS 09689
47. Vespa P, Prins M, Ronne-Engstrom E, Caron M, Shalmon E, Hovda DA, et al. Increase in extracellular glutamate caused by reduced cerebral perfusion pressure and seizures after human traumatic brain injury: a microdialysis study. J Neurosurg. (1998) 89:971-82. doi: 10.3171/jns.1998.89.6.0971

48. Jalloh I, Helmy A, Howe DJ, Shannon RJ, Grice P, Mason A, et al. Focally perfused succinate potentiates brain metabolism in head injury patients. $J$ Cereb Blood Flow Metab. (2017) 37:2626-38. doi: 10.1177/0271678X16672665

49. Jalloh I, Carpenter KL, Helmy A, Carpenter TA, Menon DK, Hutchinson PJ. Glucose metabolism following human traumatic brain injury: methods of assessment and pathophysiological findings. Metab Brain Dis. (2015) 30:61532. doi: 10.1007/s11011-014-9628-y

50. Jalloh I, Carpenter KL, Grice P, Howe DJ, Mason A, Gallagher CN, et al. Glycolysis and the pentose phosphate pathway after human traumatic brain injury: microdialysis studies using 1,2-(13)C2 glucose. J Cereb Blood Flow Metab. (2015) 35:111-20. doi: 10.1038/jcbfm.2014.177

51. Carpenter KL, Jalloh I, Gallagher CN, Grice P, Howe DJ, Mason A, et al. (13)Clabelled microdialysis studies of cerebral metabolism in TBI patients. Eur $J$ Pharm Sci. (2014) 57:87-97. doi: 10.1016/j.ejps.2013.12.012

52. DeVience SJ, Lu X, Proctor J, Rangghran P, Melhem ER, Gullapalli $\mathrm{R}$, et al. Metabolic imaging of energy metabolism in traumatic brain injury using hyperpolarized [1-(13)C]pyruvate Sci Rep. (2017) 7:1907. doi: 10.1038/s41598-017-01736-x

53. Aygok GA, Marmarou A, Fatouros P, Kettenmann B, Bullock RM. Assessment of mitochondrial impairment and cerebral blood flow in severe brain injured patients. Acta Neurochir Suppl. (2008) 102:57-61. doi: 10.1007/978-3-211-85578-2_12

54. Ehinger JK, Piel S, Ford R, Karlsson M, Sjovall F, Frostner EA, et al. Cellpermeable succinate prodrugs bypass mitochondrial complex I deficiency. Nat Commun. (2016) 7:12317. doi: 10.1038/ncomms12317

55. Prins ML, Matsumoto JH. The collective therapeutic potential of cerebral ketone metabolism in traumatic brain injury. J Lipid Res. (2014) 55:2450-7. doi: 10.1194/jlr.R046706

56. Maalouf M, Sullivan PG, Davis L, Kim DY, Rho JM. Ketones inhibit mitochondrial production of reactive oxygen species production following glutamate excitotoxicity by increasing NADH oxidation. Neuroscience. (2007) 145:256-64. doi: 10.1016/j.neuroscience.2006.11.065

57. Arun P, Ariyannur PS, Moffett JR, Xing G, Hamilton K, Grunberg NE, et al. Metabolic acetate therapy for the treatment of traumatic brain injury. J Neurotrauma. (2010) 27:293-8. doi: 10.1089/neu.2009.0994

58. Patel SP, Sullivan PG, Lyttle TS, Magnuson DS, Rabchevsky AG. AcetylL-carnitine treatment following spinal cord injury improves mitochondrial function correlated with remarkable tissue sparing and functional recovery. Neuroscience. (2012) 210:296-307. doi: 10.1016/j.neuroscience.2012.03.006

59. Davis LM, Pauly JR, Readnower RD, Rho JM, Sullivan PG. Fasting is neuroprotective following traumatic brain injury. J Neurosci Res. (2008) 86:1812-22. doi: 10.1002/jnr.21628

60. Yoshino J, Mills KF, Yoon MJ, Imai S. Nicotinamide mononucleotide, a key $\mathrm{NAD}(+)$ intermediate, treats the pathophysiology of dietand age-induced diabetes in mice. Cell Metab. (2011) 14:528-36. doi: 10.1016/j.cmet.2011.08.014

61. Hoane MR, Akstulewicz SL, Toppen J. Treatment with vitamin B3 improves functional recovery and reduces GFAP expression following traumatic brain injury in rats. J Neurotrauma. (2003) 20:1189-99. doi: 10.1089/089771503770802871

62. Hoane MR, Kaplan SA, Ellis AL. The effects of nicotinamide on apoptosis and blood-brain barrier breakdown following traumatic brain injury. Brain Res. (2006) 1125:185-93. doi: 10.1016/j.brainres.2006.10.019

63. Hoane MR, Tan AA, Pierce JL, Anderson GD, Smith DC. Nicotinamide treatment reduces behavioral impairments and provides cortical protection after fluid percussion injury in the rat. J Neurotrauma. (2006) 23:1535-48. doi: 10.1089/neu.2006.23.1535

64. Hoane MR, Gilbert DR, Holland MA, Pierce JL. Nicotinamide reduces acute cortical neuronal death and edema in the traumatically injured brain. Neurosci Lett. (2006) 408:35-9. doi: 10.1016/j.neulet.2006.07.011

65. Hoane MR, Pierce JL, Holland MA, Anderson GD. Nicotinamide treatment induces behavioral recovery when administered up to $4 \mathrm{~h}$ following cortical contusion injury in the rat. Neuroscience. (2008) 154:861-8. doi: 10.1016/j.neuroscience.2008.04.044 
66. Ying W. NAD+ and NADH in brain functions, brain diseases and brain aging. Front Biosci. (2007) 12:1863-88. doi: 10.2741/ 2194

67. Shear DA, Dixon CE, Bramlett HM, Mondello S, Dietrich WD, DengBryant Y, et al. Nicotinamide treatment in traumatic brain injury: operation brain trauma therapy. J Neurotrauma. (2016) 33:523-37. doi: $10.1089 /$ neu.2015.4115

68. Goffus AM, Anderson GD, Hoane M. Sustained delivery of nicotinamide limits cortical injury and improves functional recovery following traumatic brain injury. Oxid Med Cell Longev. (2010) 3:145-52. doi: 10.4161/oxim.3.2.11315
Conflict of Interest Statement: The authors declare that the research was conducted in the absence of any commercial or financial relationships that could be construed as a potential conflict of interest.

Copyright (c) 2019 Pandya, Leung, Yang, Flerlage, Gilsdorf, Deng-Bryant and Shear. This is an open-access article distributed under the terms of the Creative Commons Attribution License (CC BY). The use, distribution or reproduction in other forums is permitted, provided the original author(s) and the copyright owner(s) are credited and that the original publication in this journal is cited, in accordance with accepted academic practice. No use, distribution or reproduction is permitted which does not comply with these terms. 